\title{
Parents' ratings of post-discharge healthcare for their children born very preterm and their suggestions for improvement: a European cohort study
}

Anna-Veera Seppänen ${ }^{1,2 *}$, Priscille Sauvegrain ${ }^{1,3}$, Elizabeth S Draper ${ }^{4}$, Liis Toome ${ }^{5,6}$,

Rym El Rafei ${ }^{1,2}$, Stavros Petrou ${ }^{7,8}$, Henrique Barros ${ }^{9}$, Luc J I Zimmermann ${ }^{10,11}$, Marina

Cuttini $^{12}$, Jennifer Zeitlin ${ }^{1}$ and the SHIPS Research group**

\section{*Corresponding author:}

Anna-Veera Seppänen

Université de Paris, CRESS, Obstetrical Perinatal and Pediatric Epidemiology Research

Team, EPOPé, INSERM, INRA, F-75004 Paris, France

Maternité de Port-Royal, 53 Avenue de l'Observatoire, 75014, Paris, France.

E-mail: anna-veera.seppanen@inserm.fr

Telephone: +33 (0)1 42345583

**SHIPS Research Group: Belgium (J Lebeer, I Sarrechia, P Van Reempts, E Bruneel, E Cloet, A Oostra, E Ortibus); Denmark (K Boerch, P Pedersen); Estonia (L Toome, H Varendi, M Männamaa); France (PY Ancel, A Burguet, PH Jarreau, V Pierrat, A Nuytten); Germany (RF Maier, M Zemlin, B Misselwitz, L Wohlers) Italy (M Cuttini, I Croci, V Carnielli, G Ancora, G Faldella, F Ferrari); the Netherlands (A van Heijst, C Koopman-Esseboom); Poland (J Gadzinowski, J Mazela, A Montgomery, T Pikuła) Portugal (H Barros, R Costa, C Rodrigues); Sweden (U Aden); United Kingdom (ES Draper, A Fenton, SJ Johnson); EFCNI (S Mader, N Thiele, JM Pfeil); Health Economics 
team (S Petrou); Inserm Coordination (J Zeitlin, A M Aubert, C Bonnet, R El Rafei, A-V Seppänen)

\section{Affiliations}

1. Université de Paris, CRESS, Obstetrical Perinatal and Pediatric Epidemiology Research Team, EPOPé, INSERM, INRA, F-75004 Paris, France

2. Sorbonne Université, Collège Doctoral, F-75005 Paris, France

3. Department of Obstetrics and Gynecology, Pitié-Salpêtrière Hospital, AP-HP, Paris, France

4. Department of Health Sciences, University of Leicester, Leicester, United Kingdom

5. Tallinn Children's Hospital, Tallinn, Estonia

6. University of Tartu, Tartu, Estonia

7. Warwick Medical School, University of Warwick, Coventry, United Kingdom

8. Nuffield Department of Primary Care Health Sciences, University of Oxford, Oxford, United Kingdom

9. EPIUnit-Instituto de Saúde Pública da Universidade do Porto, Porto, Portugal

10. European Foundation for the Care of Newborn Infants (EFCNI), Munich, Germany

11. Department of Paediatrics, Research School for Oncology and Developmental Biology, Maastricht UMC+, Maastricht, the Netherlands

12. Clinical Care and Management Innovation Research Area, Bambino Gesù Children's Hospital, Rome, Italy 


\section{Author contributions}

AVS, ESD, LT, RER, SP, HP, MC, JZ and the SHIPS Research Group made substantial contributions to conception and design and acquisition of data. AVS, PS and JZ analyzed the data. AVS, PS, ESD, LT, RER, SP, HP, LJZ, MC and JZ contributed to interpretation of data, drafting the article, revising it critically for important intellectual content, and approved the final version to be published. Members of the SHIPS research group approved the final version to be published.

\section{Statement of financial support}

The research received funding from the European Union's Horizon 2020 Research and Innovation Programme under grant agreement No 633724. Anna-Veera Seppänen has a doctoral contract funded by Sorbonne Université Collège Doctoral, Paris, France.

\section{Disclosure}

No conflict of interest declared.

\section{Category of study}

Population study

\section{Patient consent}

Ethics approvals and parental consent were obtained according to national legislation in each country before data collection 


\section{Acknowledgement}

This is a post-peer-preview, pre-copyedit version of an article published in Pediatric Research. The final authenticate version is available online at:

http://dx.doi.org/10.1038/s41390-020-01120-y

\section{Impact Statement}

- In a European population-based very preterm birth cohort, parents rated postdischarge healthcare as poor or fair for $14.2 \%$ of children, with a wide variation $(6.1 \%$ to $31.6 \%)$ between countries

- Dissatisfaction was reported in over one-third of cases when children had health or developmental difficulties, such as epilepsy or cerebral palsy

- Parents' free-text suggestions for improving preterm-related post-discharge healthcare were similar across countries; these focused primarily on better communication with parents and better coordination of care

- Parents' lived experiences are a valuable resource for understanding where care improvements are needed and should be included in future research 


\begin{abstract}
Background: Follow-up of very preterm infants is essential for reducing risks of health and developmental problems and relies on parental engagement. We investigated parents' perceptions of post-discharge healthcare for their children born very preterm in a European multi-country cohort study.

Methods: Data come from a five-year follow-up of an area-based cohort of births $<32$ weeks' gestation in 19 regions from 11 European countries. Perinatal data were collected from medical records and five-year data from parent-report questionnaires. Parents rated post-discharge care related to their children's preterm birth (poor/fair/good/excellent), and provided free-text suggestions for improvements. We analyzed sociodemographic and medical factors associated with poor/fair ratings, using inverse probability weights to adjust for attrition bias, and assessed free-text responses using thematic analysis.

Results: Questionnaires were returned for 3635 children (53.8\% response rate). Care was rated as poor/fair for $14.2 \%$ [6.1\% (France) to $31.6 \%$ (Denmark)]; rates were higher when children had health or developmental problems (e.g. cerebral palsy (34.4\%) or epilepsy $(36.9 \%))$. From 971 responses, four themes and 25 sub-themes concerning care improvement were identified.

Conclusions: Parents' experiences provide guidance for improving very preterm children's post-discharge care; this is a priority for children with health and developmental problems as parental dissatisfaction was high.
\end{abstract}




\section{Introduction}

Very preterm births (<32 weeks of gestation) represent up to $1.6 \%$ of births in high-income countries (1) or up to $2 \%$ of births worldwide (2). Although survival for these infants has improved, they remain at increased risk of developing multiple health and developmental problems compared to infants born at term $(3,4)$. As the prognosis for each individual infant is unknown at discharge from hospital, follow-up is essential for the early identification of health needs, the coordination of health services from multiple providers, and for enabling timely intervention (5).

Parents' engagement is crucial for successful follow-up of preterm infants (6), but few studies have reported on parents' own evaluations of the post-discharge care offered to their children. Parents may provide important insights for improving healthcare beyond aspects of medical, outcome-related quality $(7,8)$, and this knowledge may help to improve service adherence, care delivery (8) and, consequently, health outcomes. Qualitative studies involving parents have suggested that there is room for improvement in the continuity of care for preterm infants (9) and that assistance with accessing services or providing comprehensive information to parents may impact on the use of post-discharge services in this population (10). The use of early intervention services has been shown to improve outcomes in both children (11) and parents (12) and may be of most benefit to socially deprived families (13). At the same time, unfavorable social factors such as poorer financial resources (14) or lower educational level (15) have been associated with multiple barriers for attending follow-up services (14) and follow-up discontinuation (15) for children at risk of developmental problems and morbidities. 
Although parents are frequently involved in evaluating specific healthcare services or units $(16,17)$, pediatric specialties (18) or aspects of care (9), there have been no large scale or international evaluations of post-discharge care involving parents of children born very preterm. The main aims of this study were to assess parents' ratings of their children's prematurity-related care from discharge from neonatal care until five years of age, in a large cohort from 19 regions in 11 European countries, by sociodemographic characteristics and child health outcomes. In addition, we aimed to provide a thematic synthesis of parents' suggestions on how healthcare can be improved.

\section{Method}

\section{Data sources}

The data were collected for the Screening to improve Health In very Preterm infantS (SHIPS) study, which followed up the area-based EPICE cohort of infants born before 32 weeks' gestation over 12 months in 2011-2012 $(19,20)$, in all maternity units of 19 regions in 11 European countries: Belgium (Flanders); Denmark (Eastern region); Estonia (entire country); France (Burgundy, Ile-de-France, and Northern regions, six months' data collection only); Germany (Hesse and Saarland); Italy (Emilia-Romagna, Lazio, and Marche); the Netherlands (Central and Eastern regions), Poland (Wielkopolska); Portugal (Lisbon and Northern regions); Sweden (greater Stockholm) and the United Kingdom (East Midlands, Northern, and Yorkshire and the Humber regions). Children were followed up at two and five years of age using parental questionnaires. At five years of age, a sub-set of all children born before 28 weeks' gestation were also invited to participate in clinical assessments (19). 


\section{Ethics}

Ethics approvals and parental consent were obtained according to national legislation in each country before data collection. The SHIPS project was approved by the French Advisory Committee on Use of Health Data in Medical Research (CCTIRS) and the French National Commission for Data Protection and Liberties (CNIL).

\section{Study population}

At baseline, the cohort included 7900 live births and 2429 stillbirths and terminations of pregnancies. 6792 infants were discharged alive from the neonatal unit (Supplemental Figure S1 (online)). At five years, 6759 children were alive, of whom parents of 3687 $(54.5 \%)$ children participated in the follow-up and 3635 (53.8\%) returned a questionnaire (19).

\section{Data collection}

At inclusion, pregnancy and perinatal data were collected from obstetric and neonatal records. At five years of age, health, healthcare and socioeconomic information was collected using parent-report questionnaires that had been pre-tested in all national languages. The questionnaires could be completed at home, in follow-up clinics, online or using paper questionnaires, depending on local study protocols. Questionnaires could be filled in by mothers, fathers or other primary caregivers. They were asked the following question: "How would you describe the healthcare your child has received related to his or her preterm birth after being discharged from the neonatal unit; excellent, good, fair, poor, 
or has not received any healthcare related to very preterm birth?". The parents were also asked to provide suggestions for how healthcare for very preterm children can be improved, as free-text responses.

\section{Data analysis}

Proportions of poor to fair ratings (considered to represent dissatisfaction) were described by country. The association between dissatisfaction, and sociodemographic characteristics and child health was assessed using $\chi^{2}$ tests. Sociodemographic characteristics included maternal educational level (lower: lower secondary [ISCED levels 0-2], intermediate: upper or post-secondary, non-tertiary or short cycle tertiary [levels 3-5], or higher: Bachelor degree or higher [levels 6-8]) (21), country of birth (native-born, born elsewhere in Europe or born outside Europe), family situation (mother living with partner vs. single caregiver or other family situation), age at delivery ( $\leq 24,25-34$ or $\geq 35$ years), parity at delivery (multiparous vs. nulliparous), and multiplicity (singleton vs. twins or more). As in previous analyses of this cohort, perinatal risk factors were used to create a variable representing overall risk of health and developmental problems at discharge from the neonatal hospitalization, classified as: lower (born over 29 weeks' gestation, not small for gestational age [SGA; birthweight <10th centile for intrauterine norms for gestational age and sex, using references developed for the cohort (22)] and without severe neonatal morbidities [bronchopulmonary dysplasia (BPD), i.e. need for supplemental oxygen or ventilation at 36 weeks' postmenstrual age, stages III-V retinopathy of prematurity (ROP), levels III-IV intraventricular hemorrhage (IVH), cystic periventricular leukomalacia (cPVL), or necrotizing enterocolitis (NEC) needing surgery] or congenital anomalies 
[CA]), moderate (not classified as higher or lower risk) or higher risk (born below 28 weeks' gestation or at least one neonatal morbidity or a severe CA) (23). Data on the child's health at five years included a parental rating of their child's overall health status (good/excellent vs. poor/fair) and asthma diagnosis. Data on developmental and neurosensory difficulties included the parent's rating of their child's development (average/advanced vs. delayed/very delayed), clinical diagnosis of cerebral palsy, epilepsy and autism, and reports of moderate or severe vision or hearing problems (defined as having difficulties seeing even with glasses, being blind or seeing light only, requiring hearing aids, or being deaf).

To obtain adjusted risk ratios for dissatisfaction with healthcare services, we used three multilevel generalized linear regression models with a log link, Poisson distribution and a robust variance estimator (24), with two levels to account for correlation between siblings: one including sociodemographic variables and country only, and two adding either parentrated health and developmental problems or diagnosed developmental or neurosensory difficulties. We did not run a model with all variables due to collinearity between parentreported health status and clinical diagnoses. The covariates were selected based on the scientific literature and bivariate analyses, including variables that were related to parental ratings with a $\mathrm{p}$-value $<0.2$. We used the sample average as the reference for presenting the country risk ratios for poor/fair ratings. In sensitivity analyses, regression models were (1) adjusted for all covariates without selection based on a p-value cut-off and (2) restricted to cases where the questionnaire was answered by mothers only. 


\section{Non-response and missing data}

The response rate varied depending on the country (53.8\% overall, range 29.3 to $96.4 \%$ ); non-responders in the cohort were more likely to be younger, foreign-born mothers and have a lower educational level, as detailed elsewhere (19). To take into consideration potential attrition bias, we generated inverse probability weights based on characteristics of non-responders available at baseline and at the two-year follow-up, after multiple imputation of missing values (25), following methods previously used in this cohort (26). This approach gives a higher weight to children with characteristics that are underrepresented because of non-response. First, twenty imputations using multiple chained equations were performed to impute missing values for the variables used for predicting the inverse probability weights. Data were assumed to be missing at random. All variables associated with loss to follow-up were included in the regression: gestational age in completed weeks, Apgar score $(<7)$, use of continuous positive airway pressure (CPAP), use of mechanical ventilation, use of prophylactic surfactant within two hours after birth, birth in level 3 unit, inborn status (no transfer within 48h of birth), SGA, any CA (severe or non-severe vs none), BPD, any severe morbidity at discharge (IVH or cPVL, ROP or NEC), surgery (for patent ductus arteriosus, CA, NEC or other reasons), infant received human milk at discharge, mode of delivery (vaginal/instrumental vs caesarean), previous

caesarean section, parity at delivery, antepartum hemorrhage after week 20, premature rupture of membranes $(>12 \mathrm{~h})$, multiplicity, mother's age at delivery, mother's country of birth, mother's educational level, gross motor impairment at 2 years corrected age (27) and cognitive delay at 2 years corrected age (27) and study region. The weights were estimated on the total sample of infants eligible for follow-up at 5 years. All proportions in the tables 
are derived from the weighted sample and all models were run with weights. In sensitivity analyses, we ran models truncating weight values at the $95^{\text {th }}$ percentile to assess whether the results were affected by the extremes of the weight distribution.

Missing data were not frequent among responders: $2.7 \%$ of healthcare ratings were missing and the proportion of missing data varied between $0.3 \%$ (maternal age) and $5.3 \%$ (country of origin) for co-variables.

\section{Analysis of free-text responses}

Free-text responses were explored using thematic analysis. We used an iterative process for the translation of responses and initial coding into keywords and subthemes. The approximately 1300 free-text responses were first automatically translated using Google Translate. Tables including the original juxtaposed with the automatically translated text were used for a first coding of keywords and preliminary themes by the first author. In this step, specific ambiguities in the translations or where multiple interpretations were possible were highlighted. These tables were then sent to the country teams who reviewed the translations and key words. The focus of this step was to ensure that the text was correctly translated and that these translations, as well as the keywords, reflected the original content. As it was not possible to return questionnaires to the responders for clarifications, responses that could not be interpreted after review, due to poor wording or lack of detail, were removed. After this step, keywords were coded into themes and subthemes by the first author, which were reviewed and validated by a qualitative researcher (PS); a random sample of the responses were double-coded by PS and divergences were discussed with the 
first author until consensus was reached. Responses that contained more than one suggestion were coded into several themes and duplicate responses for multiple siblings were removed. Themes and subthemes were summarized and described by country and healthcare ratings. Citations were extracted to illustrate the most common subthemes, while ensuring the confidentiality of the responder. The citations selected for presentation in the manuscript were reviewed again by country team members to ensure the precision of the translation.

All data analyses were carried out with STATA 14.0 (Stata Corp., College Station, TX, USA) and Excel 2013.

\section{Results}

Questionnaires were returned for 3635 children; by mothers (83\%), fathers (15\%) and other caretakers, such as grandparents (1.4\%), all hereafter referred to as parents. Parents reported that $92.8 \%$ of the children had received post-discharge care for their prematurity. For $14.2 \%$ of these children, parents judged the care to be poor or fair, but this varied from 6.1\% in France to $31.6 \%$ in Denmark. (Table 1). Parents expressed more dissatisfaction with post-discharge care when maternal educational level was higher and when mothers were native-born or born outside Europe compared to mothers born elsewhere in Europe (Table 2). Proportions of poor/fair ratings were higher for children with parent-rated health or developmental problems, diagnosed cerebral palsy or epilepsy, or moderate to severe vision or hearing problem at five years of age. 
Higher maternal educational level, being native-born and child health and developmental difficulties remained associated with poor/fair ratings in the adjusted analyses (Table 3). Significant differences in risk ratios persisted across countries after adjustment, despite slight changes in point estimates. Incorporating remaining covariates (mother's age, parity, multiple birth and asthma diagnosis, $\mathrm{p}$-value $>0.2$ ) in our sensitivity analysis did not change these associations (data not shown). Sensitivity analysis with only mothers as responders showed slightly higher rates of dissatisfaction ( $15.0 \%$ instead of $14.2 \%)$, but did not change the results from the main models (data not shown). Differences between weighted and unweighted proportions of poor and fair ratings were minimal: 13.5\% [95\% CI 12.3-14.7] versus 14.2\% [95\% CI 12.9-15.6] overall (see Supplemental Table S1 (online) for unweighted proportions by country) and associations with other co-variables in unweighted and weighted models were similar (Supplemental Table S2 (online)), but slightly increased the association between mother's educational level and dissatisfaction as well as perinatal health and dissatisfaction. Sensitivity analyses truncating weights at the $95^{\text {th }}$ percentile $(\mathrm{n}=52$ at weight=4.24) did not affect results. See Supplemental Table S2 (online) for models (Model III) with and without truncated weights, compared to unweighted models. Parents provided 1105 (30\%) unique free-text responses, of which 85 stated 'no comment' or 'do not know' and 49 that the child had not received post-discharge care. The remaining 971 responses were analyzed thematically. Some themes did not relate to improvements in post-discharge healthcare, but focused on positive experiences with healthcare $(n=232$ suggestions) or care during the neonatal hospitalization ( $\mathrm{n}=137$ suggestions) and were excluded. Four themes and 25 subthemes were related to healthcare improvements, as shown in Table 4. Among the parents who provided free-text responses, 956 also rated the 
post-discharge care; $25.7 \%(n=246)$ rated the care as poor or fair and $74.3 \%(n=710)$ as good or excellent (not shown).

The most frequent theme was I. Coordination of follow-up and healthcare, with Improving care coordination as the most common subtheme. Parents reported a lack of coordination, having to take responsibility for the organization of healthcare and identification of the appropriate healthcare providers for their child, which was described as an exhausting, stressful, time consuming or difficult task. Some parents experienced having numerous appointments with poor continuity of care and lack of communication between multiple healthcare providers, or asked for a reference person to coordinate care or follow-up.

"Big disappointment that no one has overall responsibility for follow-up. Our daughter has many doctor visits at three different hospitals. Countless visits could have been avoided if someone had an overview of the situation." - Parent, Sweden (care rating:

$$
\text { Poor) }
$$

Other reoccurring subthemes in this category included the need for further training of generalists and nurses (especially health visitors and Child Healthcare Centre nurses) on preterm birth, having more equitable access to follow-up and services, and reducing waiting times on waiting lists, especially for visits to specialists, and queuing in the waiting rooms.

"After finishing the follow-up at the neonatal unit, we find that both the Child Healthcare Centre nurse and the preschool lack knowledge of premature babies and their needs. Thus, more knowledgeleducation to Child Health Centre and preschool staff." - Parent, Sweden (care rating: Excellent) 
"Unfortunately, help for premature babies is only available in larger cities. We live in the countryside and have limited access to all specialists. A visit to a specialist is associated with an additional trip, and I do not always have a transport and unfortunately there is still a very long waiting time for some specialists." - Parent, Poland (care rating: Good)

The second most frequent theme was II. Follow-up type and content. Two common suggestions included having more frequent or longer follow-up. The reasons included reassuring parents that the child was reaching important developmental milestones, to know whether the child was ready for school and/or needed school support. A few parents felt that follow-up was unnecessary when their child was doing well.

"There should be a follow-up when the children reach school age to see how they are developing and whether they are ready to go to school." - Parent, Denmark (care rating:

Fair)

Improving follow-up with additional examinations or therapies, especially before school start, and following up on other areas apart from physical health, such as emotional and mental health, were two frequent subthemes in this category.

"Preterm children could have a check every year, especially hearing, vision and psychologist. There should definitely be a check before school." - Parent, Estonia (care rating: Good) 
"Follow-up on physical health was fine. Follow-up on mental health and "invisible" late effects were non-existent. We were all alone with those things and ended up seeking help from a private consultant." - Parent, Denmark (care rating: Poor)

Improving healthcare professionals' communication with parents, in category III. Communication and parent support, was the most frequent subtheme overall. Main issues were lack of communication from healthcare providers and lack of information sharing with parents regarding medical procedures, follow-up and medical services available, how to care for a child born very preterm and what to expect regarding the child's long-term health or schooling. Some suggestions concerned interpersonal aspects, such as lack of empathy or listening, or requesting a more humane or positive attitude from healthcare providers.

"It was explained in the neonatal unit that in the future we may come across problems such as learning difficulties, vision, hearing, developmental delay. However, it was never explained if and what services would help overcome any of these problems." - Parent, UK (care rating: Poor)

Parents also frequently suggested psychological or emotional support for the parents themselves as part of the long-term follow-up after discharge. They expressed a feeling of being left alone to cope with the trauma of very preterm birth, and the burden of taking care of their child after discharge, without sufficient psychological support for both parents.

"I, as a mother, would have wished for better support after discharge. After the hospital stay, you are left alone with your worries and fears". - Parent, Germany (care rating:

Excellent) 
"Making room for parents too, because also the motherhood was premature." - Parent, Italy (care rating: Fair)

Subthemes were similar across countries (not shown), and similarly ranked for parents who rated the healthcare as poor or fair and those who rated healthcare as good or excellent.

\section{Discussion}

Overall, $14.2 \%$ of the children in our study received healthcare that their parents rated as poor or fair, with variation between $6.1 \%$ and $31.6 \%$ by country. However, dissatisfaction was significantly higher for children with health or developmental problems; up to over one-third when children had a diagnosis of cerebral palsy or epilepsy or when parents rated their children's health as poor or fair. Dissatisfaction with post-discharge care was more frequent among mothers with higher educational status. Thematic analysis of 971 parental responses identified four themes and 25 subthemes about how healthcare could be improved, which were largely similar across countries.

The strengths of this study include its population-based design, geographic diversity, large sample size and the use of a standardized, pre-tested questionnaire. A strength, but also a limitation of the study is the wide definition of post-discharge healthcare covering the period between NICU discharge and five years of age. As follow-up programs and health services vary across countries in terms of availability, content and duration, our questionnaire intentionally referred to a large range of services over a long period of time. Thus, we are able to measure overall perceptions with how very preterm birth is managed in the long term across countries, but we cannot know if parents referred to specific care 
aspects in their ratings (medical quality, screening, interventions etc.), unless parents specified the service or time period in the free-text answers. The free-text question intentionally leads parents towards more negative experiences, as it focused on aspects requiring improvement in care. However, the long time period may lead parents to refer care ratings either to more recent care, or care related to more difficult and stressful experiences, which may have happened around NICU discharge and in early childhood when medical follow-up is more intense. In the latter case, the ratings may be more negative than if the question had covered a more proximate period. Unfortunately, we did not have data on the characteristics of services received nor objective measures of the quality of services, such as waiting times or service availability, to contrast with parental perceptions. Another potential limitation relates to the multilingual nature of our sample, in particular when interpreting the free-text responses. When translation is part of the research process, it inevitably involves a degree of interpretation (28), and may increase the risk of misinterpretation of answers (29). To minimize this risk, we used an iterative process for the translation and interpretation using automatic translation, followed by coding of keywords and finally a review of translation accuracy and interpretation by researchers in each of the study countries. A final limitation was the potential for bias linked to nonresponse, which was $45.5 \%$ for the overall sample and higher in some countries (19). Loss to follow-up is a challenge in longitudinal cohort studies (30), especially those with population-based designs, and can be related to characteristics that may affect healthcare perceptions. We used inverse probability weights to adjust for attrition bias. Reassuringly, results based on the unweighted and weighted analyses were similar, but slightly increased the association between mother's educational level and dissatisfaction as well as perinatal 
health and dissatisfaction. Previous studies in this cohort have shown that the association between sociodemographic or perinatal factors and health-related outcomes may be accentuated when using these weights (21), as increased loss to follow-up in socially disadvantaged groups is taken into account.

The proportion of poor/fair ratings varied widely across countries. The study countries differ on several structural aspects that may have contributed to these differences, but that we were not able to measure, such as the organization of primary care (31), level of integrated care in the case of multi-morbidity (31), patients' ability to pay for out of pocketcosts (32), and the state's involvement in the healthcare system (33). Furthermore, followup and subsequent care are likely to have been organized very differently across the regions, including access to specialists (23), as no international standards for follow-up existed at the time. Follow-up programs aim to facilitate care coordination and timely intervention, and might in its absence have contributed to differences in overall satisfaction. Our study was not designed to link parental perceptions to specific health system features and this remains an area for further research. Differences in ratings could also be related to factors unrelated to the healthcare system. Research on adult patients has proposed that care satisfaction is to a large extent influenced by individual factors such as personality, expectations about healthcare and health status (34). Patient expectations, in turn, have been associated with several characteristics, including patient age and educational level $(34,35)$, which could explain the association between parents' educational status and dissatisfaction in our study. Unknown broader societal factors (34) may explain the differences in ratings that remained across countries after adjusting for child health and 
parent sociodemographic factors. The subjectivity of the satisfaction measure in our study may accentuate the impact of individual and social factors (36), which involve expectations and for which there is no common base level (36), as well as different levels of "tolerance" towards service quality, which may depend on the general standard of living in the country (36). This may partly explain the differences in ratings for native, European and nonEuropean-born mothers. Finally, the inclination to express dissatisfaction or complaints may also be cultural (37) and influence levels of dissatisfaction across countries, but there is, to our knowledge, little evidence on the impact of culture on care perceptions across Europe. The unexplained differences in parents' perceptions may partly mean that care satisfaction represents something different in each country (38).

The parents' suggestions concerning how healthcare could be improved were predominantly the same across countries. The suggestions were mainly organizational (follow-up coordination, provider training, access to services and timeliness), but the most frequently mentioned subtheme concerned interpersonal aspects (healthcare-provider communication and relationship with parents). Similar themes have been found in other studies $(7,9,10,16,39,40)$, suggesting that healthcare providers may be subject to similar shortcomings regardless of follow-up content and healthcare context. Of note was that many parents had suggestions for improving healthcare despite rating their care as good or excellent, and these were largely similar to parents expressing dissatisfaction. This apparently paradoxical result suggests that even parents who are satisfied with their care in general experience difficulties with care coordination or have unsatisfactory interactions with providers. 
Parents of children with health or developmental problems were less satisfied with healthcare, but few suggestions centered on health outcomes, medical quality or technical aspects of care. Other studies have found that dissatisfaction with healthcare services does not necessarily reflect poor medical quality of care $(7,22)$, but rather poor communication, especially when patients have major disabilities (41) or complex healthcare needs (8). Additionally, poor organization of healthcare may become more apparent for parents whose children require complex multidisciplinary care compared to those with less complex health problems, not seeking healthcare to the same extent. It is also possible that dissatisfaction with health services has an impact on the further use of follow-up and health services, such as change of care provider, seeking care in the private sector, or discontinuing follow-up. We do not have data on unmet service need, which is particularly difficult to define in our European cohort because of differences in health care systems and this remains an area for further investigation. Our results are consistent with those from the Models of Child Health Appraised (MOCHA) study, which showed that European countries are failing to manage complex healthcare needs in the general pediatric population, with no policies for care coordination and care planning after discharge (42). The lack of integrated healthcare systems for complex care manifests as a lack of multidisciplinary care and inconsistent healthcare provision depending on where care is sought, and may ultimately negatively affect quality of care and health outcomes (43). The parents' suggestions in our study coincide with policy improvements currently being recommended for the follow-up of preterm births, such as multidisciplinary follow-up (44), 
follow-up until school age (45) and parent support (46). Further improvements based on parents' lived experiences should be considered in policy strategies.

Over one in ten children born very preterm received post-discharge care that their parents rated as poor or fair, with the highest rates for children who are most reliant on health services. Many parents provided suggestions for improving care, which centered on common themes, despite the wide geographic heterogeneity in ratings. Parents constitute a valuable resource for researchers and policy makers seeking to improve healthcare and for understanding failures in the healthcare system. 


\section{References}

1. Delnord, M., et al. Variations in very preterm birth rates in 30 high-income countries: are valid international comparisons possible using routine data? BJOG 124:785-794 (2017).

2. Blencowe, H., et al. National, regional, and worldwide estimates of preterm birth rates in the year 2010 with time trends since 1990 for selected countries: a systematic analysis and implications. Lancet 379:2162-2172 (2012).

3. Saigal, S. \& Doyle, L.W. An overview of mortality and sequelae of preterm birth from infancy to adulthood. Lancet 371:261-269 (2008).

4. Synnes, A., et al. Determinants of developmental outcomes in a very preterm Canadian cohort. Arch. Dis. Child Fetal Neonatal Ed. 102:F235-F234 (2017).

5. McManus, B.M., Richardson, Z., Schenkman, M., Murphy, N. \& Morrato, E.H. Timing and Intensity of Early Intervention Service Use and Outcomes Among a Safety-Net Population of Children. JAMA Netw. Open 2:e187529 (2019).

6. Little, A.A., Kamholz, K., Corwin, B.K., Barrero-Castillero, A. \& Wang, C.J. Understanding Barriers to Early Intervention Services for Preterm Infants: Lessons From Two States. Acad. Pediatr. 15:430-438 (2015).

7. Gustavsson, S., Gremyr, I. \& Kenne Sarenmalm, E. Designing quality of care-contributions from parents: Parents' experiences of care processes in paediatric care and their contribution to improvements of the care process in collaboration with healthcare professionals. J. Clin. Nurs. 25:742-751 (2016).

8. Junewicz, A. \& Youngner, S.J. Patient-satisfaction surveys on a scale of 0 to 10 : improving health care, or leading it astray? Hastings Cent. Rep. 45:43-51 (2015). 
9. Rucci, P., et al. Measuring parents' perspective on continuity of care in children with special health care needs. Int. J. Integr. Care 15:e046 (2015).

10. Pritchard, M.A., Colditz, P.B., Beller, E.M. \& Queensland Optimising Preterm Infant Outcomes Group. Parental experiences and preferences which influence subsequent use of post-discharge health services for children born very preterm. $J$. Paediatr. Child Health 44:281-284 (2008).

11. Spittle, A., Orton, J., Anderson, P., Boyd, R. \& Doyle, L.W. Early developmental intervention programmes post-hospital discharge to prevent motor and cognitive impairments in preterm infants. Cochrane Database Syst. Rev. 12:CD005495 (2012).

12. Benzies, K.M., Magill-Evans, J.E., Hayden, K.A. \& Ballantyne, M. Key components of early intervention programs for preterm infants and their parents: a systematic review and meta-analysis. BMC Pregnancy Childbirth 13 Suppl 1:S10 (2013).

13. Spittle, A.J., Treyvaud, K., Lee, K.J., Anderson, P.J. \& Doyle, L.W. The role of social risk in an early preventative care programme for infants born very preterm: a randomized controlled trial. Dev. Med. Child Neurol. 60:54-62 (2018).

14. Ballantyne, M., Benzies, K.M., Rosenbaum, P. \& Lodha, A. Mothers' and health care providers' perspectives of the barriers and facilitators to attendance at Canadian neonatal follow-up programs. Child Care Health Dev. 41:722-733 (2015).

15. Callanan, C., et al. Children followed with difficulty: how do they differ? J. Paediatr. Child Health 37:152-156 (2001). 
16. Butt, M.L., Pinelli, J. \& Hunsberger, M. Parents' perceptions of ambulatory neonatal follow-up programs. Journal of Neonatal Nursing 16:126-137 (2010).

17. Hagen, I.H., Iversen, V.C., Nesset, E., Orner, R. \& Svindseth, M.F. Parental satisfaction with neonatal intensive care units: a quantitative cross-sectional study. BMC health services research 19:37 (2019).

18. McIntyre, L.L. \& Zemantic, P.K. Examining services for young children with autism spectrum disorder: Parent satisfaction and predictors of service utilization. Early childhood education journal 45:727-734 (2017).

19. Zeitlin, J., et al. Cohort profile: Effective Perinatal Intensive Care in Europe (EPICE) very preterm birth cohort. Int. J. Epidemiol. 49:372-386 (2020).

20. Zeitlin, J., et al. Use of evidence based practices to improve survival without severe morbidity for very preterm infants: results from the EPICE population based cohort. BMJ 354:i2976 (2016).

21. Sentenac, M., et al. Maternal education and language development at 2 years corrected age in children born very preterm: results from a European populationbased cohort study. J. Epidemiol. Community Health 74:346-353 (2020).

22. Monier, I., et al. Fetal and neonatal outcomes of preterm infants born before 32 weeks of gestation according to antenatal vs postnatal assessments of restricted growth. Am. J. Obstet. Gynecol. 216:516 e511-516 e510 (2017).

23. Seppanen, A.V., et al. Specialist health care services use in a European cohort of infants born very preterm. Dev. Med. Child Neurol. 61:832-839 (2019).

24. Cummings, P. Methods for estimating adjusted risk ratios. Stata Journal 9:175196 (2009). 
25. Seaman, S.R., White, I.R., Copas, A.J. \& Li, L. Combining multiple imputation and inverse-probability weighting. Biometrics 68:129-137 (2012).

26. Bonnet, C., et al. Low breastfeeding continuation to 6 months for very preterm infants: A European multiregional cohort study. Matern. Child Nutr.15:e12657 (2018).

27. Johnson, S., et al. Neurodevelopmental outcomes following late and moderate prematurity: a population-based cohort study. Arch. Dis. Child Fetal Neonatal Ed. 100:F301-308 (2015).

28. Larkin, P.J., Dierckx de Casterle, B. \& Schotsmans, P. Multilingual translation issues in qualitative research: reflections on a metaphorical process. Qual. Health Res. 17:468-476 (2007).

29. Esposito, N. From meaning to meaning: the influence of translation techniques on non-English focus group research. Qual. Health Res. 11:568-579 (2001).

30. MacBean, V., Drysdale, S.B., Zivanovic, S., Peacock, J.L. \& Greenough, A. Participant retention in follow-up studies of prematurely born children. BMC Public Health 19:1233 (2019).

31. European Commission. State of health in the EU: Companion report 2017. (Publications Office of the European Union, Luxembourg, 2017). Available from: https://ec.europa.eu/health/sites/health/files/state/docs/2017_companion_en.pdf (Accessed 2 August 2020)

32. Stepurko, T., Pavlova, M. \& Groot, W. Overall satisfaction of health care users with the quality of and access to health care services: a cross-sectional study in six Central and Eastern European countries. BMC Health Serv. Res. 16:342 (2016). 
33. Wendt, C., Kohl, J., Mischke, M. \& Pfeifer, M. How Do Europeans Perceive Their Healthcare System? Patterns of Satisfaction and Preference for State Involvement in the Field of Healthcare. European Sociological Review 26:177$192(2009)$.

34. Bleich, S.N., Ozaltin, E. \& Murray, C.K. How does satisfaction with the healthcare system relate to patient experience? Bull. World Health Organ. 87:271-278 (2009).

35. Galle, A., Van Parys, A.S., Roelens, K. \& Keygnaert, I. Expectations and satisfaction with antenatal care among pregnant women with a focus on vulnerable groups: a descriptive study in Ghent. BMC Womens Health 15:112 (2015).

36. de Silva, A. A framework for measuring responsiveness. GPE Discussion Paper Series: No. 32 (World Health Organization, Geneva, 2000). Available from: https://www.who.int/responsiveness/papers/paper32.pdf?ua=1 (Accessed 2 August 2020)

37. Kowalewski, M. Dissatisfied and Critical Citizens: the Political Effect of Complaining. Society 56:453-460 (2019).

38. Papanicolas, I., Cylus, J. \& Smith, P.C. An analysis of survey data from eleven countries finds that 'satisfaction' with health system performance means many things. Health Aff. (Millwood) 32:734-742 (2013).

39. Butt, M.L., et al. Development and evaluation of an instrument to measure parental satisfaction with quality of care in neonatal follow-up. J. Dev. Behav. Pediatr. 30:57-65 (2009). 
40. Tran, V.-T., Riveros, C., Péan, C., Czarnobroda, A. \& Ravaud, P. Patients' perspective on how to improve the care of people with chronic conditions in France: a citizen science study within the ComPaRe e-cohort. BMJ quality \& safety 28:875-886 (2019).

41. Chang, J.T., et al. Patients' global ratings of their health care are not associated with the technical quality of their care. Ann. Intern. Med. 144:665-672 (2006).

42. Brenner, M., et al. Management and integration of care for children living with complex care needs at the acute-community interface in Europe. Lancet Child Adolesc. Health 2:822-831 (2018).

43. Brenner, M., et al. Children's complex care needs: a systematic concept analysis of multidisciplinary language. Eur. J. Pediatr. 177:1641-1652 (2018).

44. EFCNI, van Kempen, A., van Steenbrugge, G., van Wassenaer-Leemhuis, A. \& Wolke, D. European Standards of Care for Newborn Health: Coordination and integration of care after discharge home. (European Foundation for the Care of Newborn Infants, Munich, 2018). Available from: https://newborn-healthstandards.org/wp-content/uploads/2019/04/TEG_Follow_up_complete.pdf (Accessed 6 April 2020)

45. EFCNI, Jaekel, J., Johnson, S., Wolke, D. \& van Wassenaer-Leemhuis, A. European Standards of Care for Newborn Health: Meeting special needs at school. (European Foundation for the Care of Newborn Infants, Munich, 2018). Available from: https://newborn-health-standards.org/wpcontent/uploads/2019/04/TEG_Follow_up_complete.pdf (Accessed 6 April 2020) 
46. EFCNI, Houtzager, B.A., van Wassenaer-Leemhuis, A., Wolke, D., Virchez, M. European Standards of Care for Newborn Health: Parental mental health. (European Foundation for the Care of Newborn Infants, Munich, 2018). Available from: https://newborn-health-standards.org/wpcontent/uploads/2019/04/TEG_Follow_up_complete.pdf (Accessed 6 April 2020) 


\section{TABLES AND FIGURES}

Table 1. Parents' ratings of preterm birth-related healthcare by country, ordered by weighted proportion of poor or fair ratings. How would you describe the healthcare your child has received related to his or her preterm birth, after being discharged from the neonatal unit?

\begin{tabular}{|c|c|c|c|c|c|c|c|c|c|c|}
\hline \multirow[b]{2}{*}{ Country } & \multirow[b]{2}{*}{$\mathbf{N}^{\mathbf{a}}$} & \multicolumn{2}{|c|}{ Excellent } & \multicolumn{2}{|c|}{ Good } & \multicolumn{2}{|c|}{ Fair } & \multicolumn{2}{|c|}{ Poor } & \multirow{2}{*}{$\begin{array}{c}\text { Poor or fair } \\
\%^{\mathrm{b}} \\
\end{array}$} \\
\hline & & $\mathbf{n}$ & $\%^{\mathrm{b}}$ & $\mathbf{n}$ & $\%^{b}$ & $\mathbf{n}$ & $\%^{b}$ & $\mathbf{n}$ & $\%^{b}$ & \\
\hline France & 688 & 343 & 49.8 & 303 & 44.1 & 40 & 5.8 & 2 & 0.3 & 6.1 \\
\hline The Netherlands & 138 & 40 & 30.7 & 85 & 60.2 & 10 & 7.1 & 3 & 2.1 & 9.2 \\
\hline Portugal & 409 & 223 & 54.6 & 142 & 34.9 & 37 & 8.9 & 7 & 1.7 & 10.5 \\
\hline Italy & 659 & 327 & 47.6 & 259 & 41.3 & 58 & 8.8 & 15 & 2.2 & 11.1 \\
\hline Belgium & 231 & 82 & 36.0 & 120 & 52.0 & 26 & 10.8 & 3 & 1.2 & 12.0 \\
\hline Estonia & 111 & 52 & 46.9 & 44 & 39.6 & 13 & 11.7 & 2 & 1.8 & 13.5 \\
\hline Sweden & 125 & 51 & 42.5 & 49 & 39.0 & 18 & 13.2 & 7 & 5.3 & 18.5 \\
\hline UK & 376 & 179 & 47.8 & 132 & 33.0 & 48 & 12.9 & 17 & 6.3 & 19.2 \\
\hline Germany & 228 & 84 & 37.4 & 99 & 42.7 & 37 & 16.7 & 8 & 3.2 & 19.9 \\
\hline Poland & 173 & 26 & 15.0 & 103 & 59.7 & 34 & 19.6 & 10 & 5.6 & 25.2 \\
\hline Denmark & 144 & 45 & 32.6 & 52 & 35.8 & 37 & 24.4 & 10 & 7.2 & 31.6 \\
\hline Total & 3282 & 1452 & 44.0 & 1388 & 41.8 & 358 & 11.2 & 84 & 3.0 & 14.2 \\
\hline
\end{tabular}

a'Excluding missing values and cases where parents reported 'no care received'

${ }^{\mathrm{b}}$ Inverse probability weights have been used to adjust for non-response 
Table 2. Poor or fair ratings by sociodemographic factors, child health and health service use.

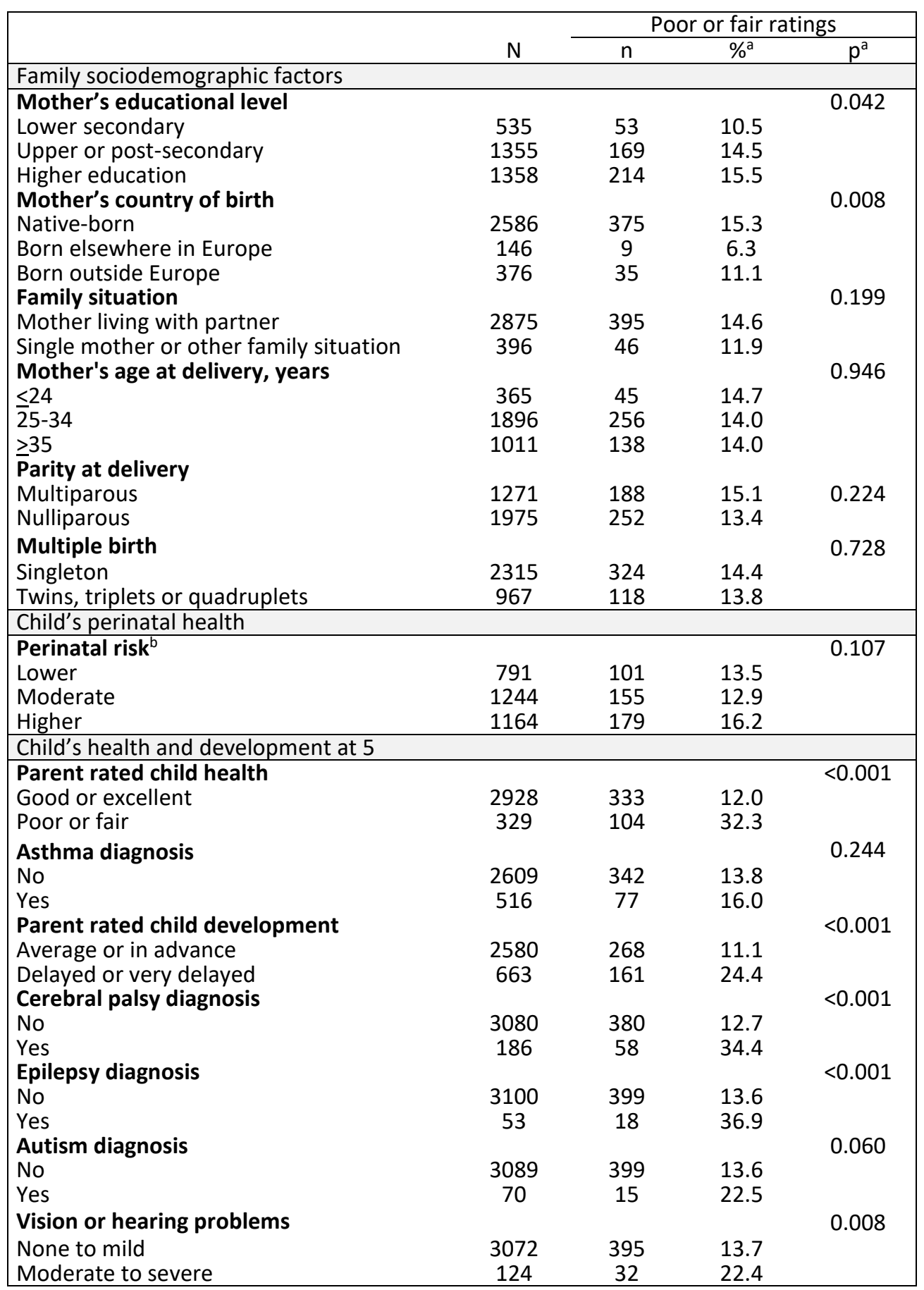

Data reported as number of children in each category $(\mathrm{N})$, and number and proportion of children with poor or fair ratings (n, \%).

aProportions are calculated using inverse probability weights

'Lower: > 29 weeks' gestation, not small for gestational age, no severe neonatal morbidities, and no congenital anomaly; Moderate: not classified as higher or lower risk; Higher: $<28$ weeks' gestation or at least one neonatal morbidity or severe congenital anomaly 
Table 3. Risk ratios of poor or fair ratings by sociodemographic characteristics and child health and development

\begin{tabular}{|c|c|c|c|c|c|c|c|c|}
\hline & \multicolumn{2}{|c|}{ Unadjusted Risk Ratios } & \multicolumn{2}{|c|}{$\begin{array}{l}\text { Model I: } \\
\text { sociodemographic } \\
\text { characteristics }\end{array}$} & \multicolumn{2}{|c|}{$\begin{array}{l}\text { Model II: socio- } \\
\text { demographic } \\
\text { characteristics and parent- } \\
\text { rated health and } \\
\text { development }\end{array}$} & \multicolumn{2}{|c|}{$\begin{array}{l}\text { Model III: socio- } \\
\text { demographic } \\
\text { characteristics, perinatal } \\
\text { risk, developmental and } \\
\text { neurosensory difficulties }\end{array}$} \\
\hline & $\mathbf{R R}$ & {$[95 \% \mathrm{Cl}]$} & ${ }^{\mathrm{a}} \mathrm{RR}$ & {$[95 \% \mathrm{Cl}]$} & ${ }^{\mathrm{a}} \mathrm{RR}$ & {$[95 \% \mathrm{Cl}]$} & ${ }^{\mathrm{a}} \mathbf{R R}$ & {$[95 \% \mathrm{Cl}]$} \\
\hline \multicolumn{9}{|l|}{ Mother's educational level (ref. lower) } \\
\hline Intermediate & 1.28 & {$[0.90-1.83]$} & 1.18 & {$[0.81-1.72]$} & 1.34 & {$[0.95-1.90]$} & 1.21 & {$[0.82-1.79]$} \\
\hline Higher & 1.63 & {$[1.15-2.32]$} & 1.44 & [0.99-2.09] & 1.73 & {$[1.22-2.46]$} & 1.49 & {$[1.01-2.20]$} \\
\hline \multicolumn{9}{|l|}{ Mother's country of birth (ref. native) } \\
\hline Born elsewhere in Europe & 0.36 & {$[0.16-0.77]$} & 0.35 & {$[0.15-0.81]$} & 0.37 & {$[0.17-0.83]$} & 0.40 & {$[0.18-0.90]$} \\
\hline Born outside Europe & 0.60 & {$[0.40-0.90]$} & 0.80 & {$[0.53-1.21]$} & 0.74 & {$[0.50-1.09]$} & 0.82 & {$[0.53-1.25]$} \\
\hline Single parent or other (ref. living with partner) & 0.81 & {$[0.56-1.18]$} & 0.90 & [0.61-1.33] & 0.85 & {$[0.57-1.26]$} & 0.88 & {$[0.58-1.34]$} \\
\hline Poor/fair health (ref. good/excellent) & 3.09 & {$[2.45-3.92]$} & & & 2.59 & [1.98-3.39] & & \\
\hline $\begin{array}{l}\text { Delayed/very delayed development } \\
\text { (ref. average/in advance) }\end{array}$ & 2.62 & [2.13-3.23] & & & 1.92 & {$[1.52-2.42]$} & & \\
\hline \multicolumn{9}{|l|}{ Perinatal risk (ref. lower) } \\
\hline Moderate & 0.93 & {$[0.71-1.23]$} & & & & & 0.97 & {$[0.75-1.25]$} \\
\hline Higher & 1.25 & [0.95-1.66] & & & & & 1.09 & {$[0.82-1.46]$} \\
\hline Cerebral palsy & 2.91 & {$[2.14-3.95]$} & & & & & 2.08 & {$[1.44-3.00]$} \\
\hline Epilepsy & 2.53 & {$[1.57-4.08]$} & & & & & 1.92 & {$[1.07-3.46]$} \\
\hline Autism & 1.78 & [1.04-3.05] & & & & & 1.37 & {$[0.76-2.46]$} \\
\hline Moderate/severe vision or hearing problem & 2.25 & [1.52-3.34] & & & & & 1.65 & [1.01-2.69] \\
\hline \multicolumn{9}{|l|}{ Country (ref. mean) } \\
\hline Belgium & 0.72 & {$[0.47-1.11]$} & 0.66 & {$[0.43-1.03]$} & 0.63 & {$[0.41-0.97]$} & 0.70 & {$[0.44-1.11]$} \\
\hline Denmark & 2.67 & [1.89-3.77] & 2.81 & [1.99-3.96] & 2.95 & {$[2.10-4.14]$} & 2.91 & {$[2.03-4.19]$} \\
\hline Estonia & 1.02 & {$[0.60-1.73]$} & 0.91 & {$[0.53-1.56]$} & 0.80 & {$[0.46-1.40]$} & 0.75 & {$[0.41-1.38]$} \\
\hline France & 0.40 & {$[0.29-0.56]$} & 0.42 & {$[0.30-0.60]$} & 0.46 & {$[0.33-0.65]$} & 0.46 & {$[0.32-0.66]$} \\
\hline Germany & 1.38 & [0.97-1.97] & 1.44 & [0.92-2.23] & 1.53 & [1.00-2.34] & 1.47 & {$[0.93-2.32]$} \\
\hline Italy & 0.73 & [0.55-0.96] & 0.81 & [0.61-1.07] & 0.81 & [0.62-1.05] & 0.83 & {$[0.62-1.10]$} \\
\hline Netherlands & 0.54 & [0.29-1.00] & 0.53 & [0.29-0.98] & 0.58 & [0.32-1.07] & 0.52 & {$[0.27-1.02]$} \\
\hline Poland & 2.07 & [1.49-2.88] & 1.93 & [1.39-2.68] & 1.80 & [1.31-2.48] & 1.95 & {$[1.40-2.72]$} \\
\hline Portugal & 0.72 & [0.52-1.00] & 0.77 & [0.55-1.07] & 0.83 & [0.60-1.14] & 0.78 & {$[0.56-1.10]$} \\
\hline Sweden & 1.38 & [0.88-2.18] & 1.36 & [0.87-2.15] & 1.26 & [0.81-1.98] & 1.41 & {$[0.85-2.34]$} \\
\hline United Kingdom & 1.13 & [0.84-1.52] & 1.12 & [0.82-1.53] & 1.06 & {$[0.78-1.45]$} & 1.03 & {$[0.72-1.46]$} \\
\hline
\end{tabular}

All risk ratios are derived from weighted, multilevel generalized linear regression models, accounting for correlation between siblings 
Table 4. Free-text themes and subthemes ordered by number of suggestions and with ranking by healthcare rating

\begin{tabular}{|c|c|c|c|c|c|}
\hline \multicolumn{6}{|c|}{ In your experience, how could the healthcare for very preterm children be improved? } \\
\hline \multirow{2}{*}{$\begin{array}{l}\text { Theme } \\
\text { (N } \\
\text { suggestio } \\
\text { ns) }\end{array}$} & \multirow[t]{2}{*}{ 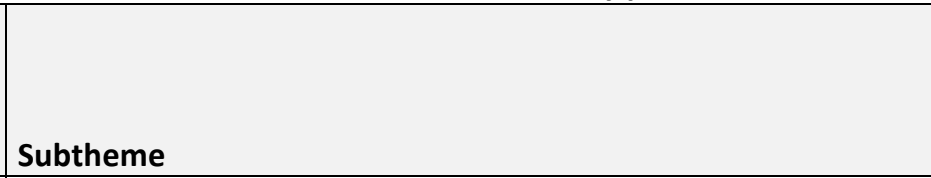 } & \multirow{2}{*}{$\begin{array}{c}\text { N } \\
\text { suggest } \\
\text { ions }\end{array}$} & \multicolumn{3}{|c|}{ Rank } \\
\hline & & & All & $\begin{array}{c}\text { Good/ } \\
\text { excellent }\end{array}$ & $\begin{array}{l}\text { Poor/ } \\
\text { fair }\end{array}$ \\
\hline \multirow{8}{*}{ 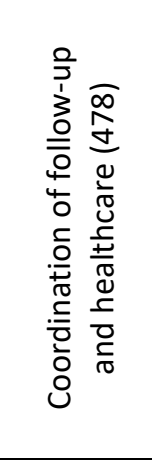 } & Improve care coordination between providers & 150 & 2 & 2 & 1 \\
\hline & Train generalists or follow-up staff about prematurity & 69 & 6 & 9 & $5 / 6$ \\
\hline & Provide more equitable access to follow-up & 68 & 7 & 6 & $5 / 6$ \\
\hline & Shorten waiting times and queuing & 60 & 9 & 8 & 8 \\
\hline & $\begin{array}{l}\text { Involve additional or more appropriate healthcare providers in } \\
\text { follow-up }\end{array}$ & 47 & 11 & & $10^{\mathrm{a}}$ \\
\hline & Improve timeliness of healthcare or follow-up & 42 & 12 & & \\
\hline & Improve hospital transfer and re-hospitalization practices & 22 & 16 & & \\
\hline & Reduce out-of-pocket costs & 20 & 18 & & \\
\hline \multirow{7}{*}{ 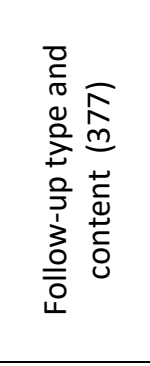 } & Improve follow-up frequency & 103 & 3 & 3 & 3 \\
\hline & Increase follow-up duration & 84 & 4 & 5 & 4 \\
\hline & Offer specific examinations or therapies & 61 & 8 & 7 & 9 \\
\hline & Offer follow-up beyond physical health & 56 & 10 & 10 & $10^{\mathrm{a}}$ \\
\hline & Change nature or type of follow-up & 27 & 14 & & \\
\hline & Improve general quality of follow-up or content & 25 & 15 & & \\
\hline & Offer home visits or home care & 21 & 17 & & \\
\hline \multirow{4}{*}{ 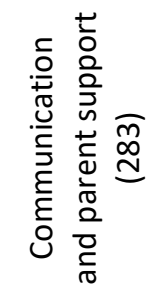 } & $\begin{array}{l}\text { Improve communication with parents or interpersonal } \\
\text { relationship }\end{array}$ & 166 & 1 & 1 & 2 \\
\hline & Offer parent follow-up and psychological or emotional support & 75 & 5 & 4 & 7 \\
\hline & Offer practical support to parents & 33 & 13 & & \\
\hline & Facilitate parents' peer-to-peer communication & 9 & 20 & & \\
\hline \multirow{6}{*}{ 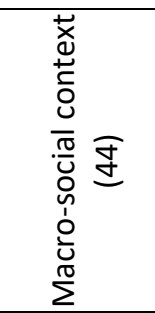 } & Train school staff about prematurity & 14 & 19 & & \\
\hline & Increase length of parental leave & 9 & 21 & & \\
\hline & Offer school support for child & 8 & 22 & & \\
\hline & Invest in research on prematurity or related healthcare & 5 & 23 & & \\
\hline & Increase healthcare investment & 5 & 24 & & \\
\hline & Improve media coverage of premature birth & 3 & 25 & & \\
\hline
\end{tabular}

In bold type: top 10 themes overall and by rating.

${ }^{\mathrm{a}}$ Equal number of suggestions 
Supplemental Figure S1. Flowchart

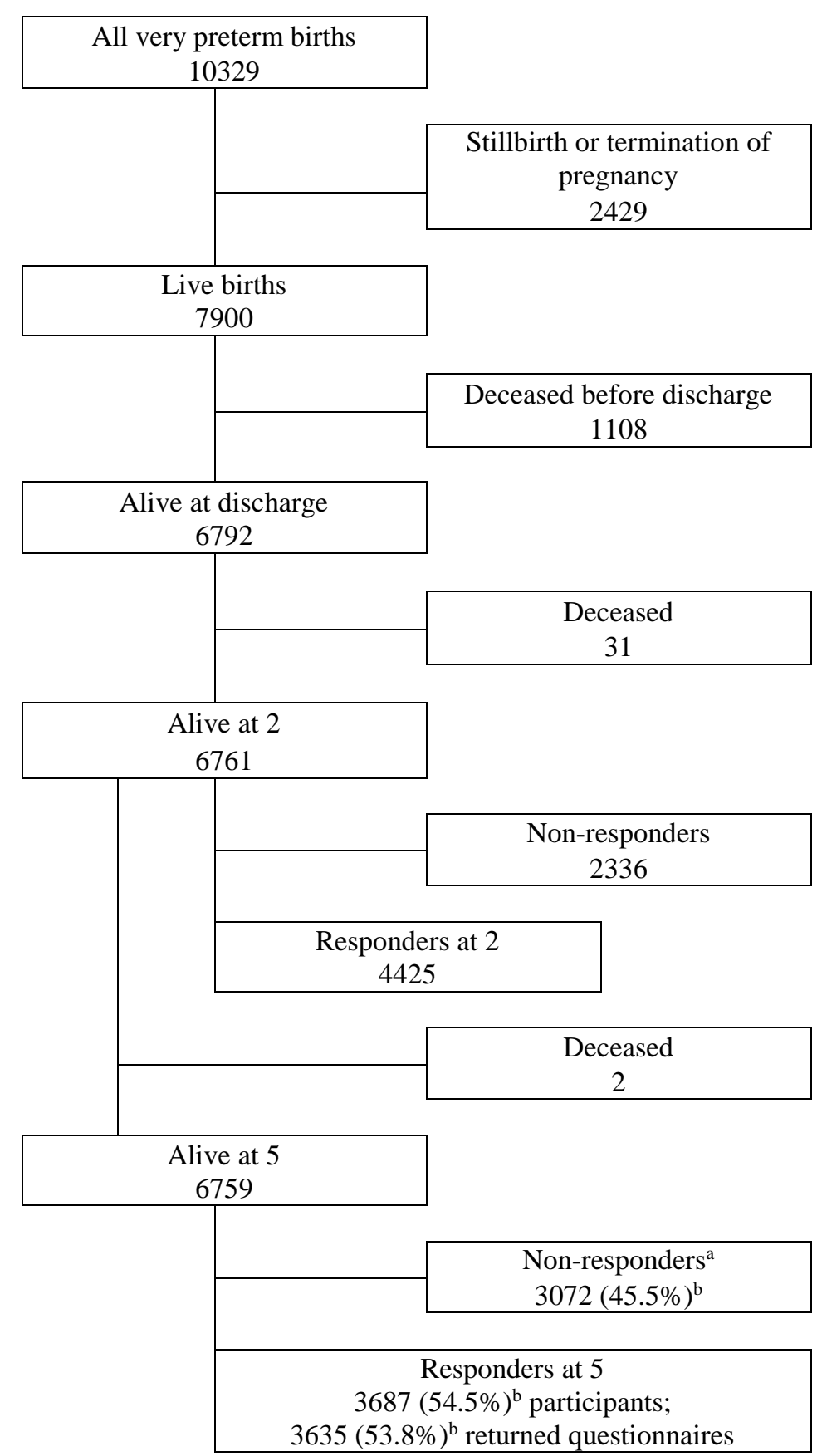

${ }^{a}$ Non-responders include children for whom parents did not consent to follow-up, who were lost to follow-up or for whom a questionnaire was not returned ${ }^{\mathrm{b}}$ Calculated over children alive at five year 
Supplemental Table S1. Parents' ratings of preterm birth-related healthcare by country, ordered by unweighted proportion of poor or fair ratings

\begin{tabular}{|c|c|c|c|c|c|c|c|c|c|c|}
\hline \multirow[b]{2}{*}{ Country } & \multirow[b]{2}{*}{$\mathbf{N}^{\mathrm{a}}$} & \multicolumn{2}{|c|}{ Excellent } & \multicolumn{2}{|c|}{ Good } & \multicolumn{2}{|c|}{ Fair } & \multicolumn{2}{|c|}{ Poor } & \multirow{2}{*}{$\frac{\text { Poor or fair }}{\%}$} \\
\hline & & $\mathbf{n}$ & $\%$ & $\mathbf{n}$ & $\%$ & $\mathbf{n}$ & $\%$ & $\mathbf{n}$ & $\%$ & \\
\hline France & 688 & 343 & 49.9 & 303 & 44.0 & 40 & 5.8 & 2 & 0.3 & 6.1 \\
\hline The Netherlands & 138 & 40 & 29.0 & 85 & 61.6 & 10 & 7.3 & 3 & 2.2 & 9.4 \\
\hline Portugal & 409 & 223 & 54.5 & 142 & 34.7 & 37 & 9.1 & 7 & 1.7 & 10.8 \\
\hline Italy & 659 & 327 & 49.6 & 259 & 39.3 & 58 & 8.8 & 15 & 2.3 & 11.1 \\
\hline Belgium & 231 & 82 & 35.5 & 120 & 52.0 & 26 & 11.3 & 3 & 1.3 & 12.6 \\
\hline Estonia & 111 & 52 & 46.9 & 44 & 39.6 & 13 & 11.7 & 2 & 1.8 & 13.5 \\
\hline UK & 376 & 179 & 47.6 & 132 & 35.1 & 48 & 12.8 & 17 & 4.5 & 17.3 \\
\hline Germany & 228 & 84 & 36.8 & 99 & 43.4 & 37 & 16.2 & 8 & 3.5 & 19.7 \\
\hline Sweden & 125 & 51 & 40.8 & 49 & 39.2 & 18 & 14.4 & 7 & 5.6 & 20.0 \\
\hline Poland & 173 & 26 & 15.0 & 103 & 59.5 & 34 & 19.7 & 10 & 5.8 & 25.4 \\
\hline Denmark & 144 & 45 & 31.3 & 52 & 36.1 & 37 & 25.7 & 10 & 6.9 & 32.6 \\
\hline Total & 3282 & 1452 & 44.2 & 1388 & 42.3 & 358 & 10.9 & 84 & 2.6 & 13.5 \\
\hline
\end{tabular}

${ }^{a}$ Excluding missing values and cases where parents reported 'no care received' 
Supplemental Table S2. Risk ratios of poor or fair ratings by sociodemographic characteristics and child health and development (A) without weights, (B) using inverse probability weights, and (C) inverse probability weights truncated at $95^{\text {th }}$ percentile

\begin{tabular}{|c|c|c|c|c|c|c|}
\hline \multirow[t]{2}{*}{$\begin{array}{l}\text { Model III: RR for poor and fair ratings by socio-demographic } \\
\text { characteristics, perinatal risk, developmental and neurosensory } \\
\text { difficulties }\end{array}$} & \multicolumn{2}{|c|}{ A) Without weights } & \multicolumn{2}{|c|}{$\begin{array}{l}\text { B) Using inverse probability } \\
\text { weights }\end{array}$} & \multicolumn{2}{|c|}{$\begin{array}{l}\text { C) Using inverse probability } \\
\text { weights truncated at } 95^{\text {th }} \\
\text { percentile }\end{array}$} \\
\hline & ${ }^{\mathrm{a}} \mathrm{RR}$ & {$[95 \% \mathrm{Cl}]$} & ${ }^{\mathrm{a}} \mathrm{RR}$ & {$[95 \% \mathrm{Cl}]$} & ${ }^{\text {a }} \mathbf{R R}$ & {$[95 \% \mathrm{Cl}]$} \\
\hline \multicolumn{7}{|l|}{ Mother's educational level (ref. lower) } \\
\hline Intermediate & 1.15 & [0.81-1.64] & 1.21 & [0.82-1.79] & 1.21 & {$[0.82-1.79]$} \\
\hline Higher & 1.38 & [0.97-1.96] & 1.49 & {$[1.01-2.20]$} & 1.49 & [1.01-2.20] \\
\hline \multicolumn{7}{|l|}{ Mother's country of birth (ref. native) } \\
\hline Born elsewhere in Europe & 0.44 & {$[0.21-0.90]$} & 0.40 & {$[0.18-0.90]$} & 0.41 & {$[0.18-0.91]$} \\
\hline Born outside Europe & 0.87 & {$[0.60-1.26]$} & 0.82 & {$[0.53-1.25]$} & 0.82 & {$[0.54-1.26]$} \\
\hline Single parent or other (ref. living with partner) & 0.92 & [0.64-1.33] & 0.88 & {$[0.58-1.34]$} & 0.88 & [0.58-1.33] \\
\hline \multicolumn{7}{|l|}{ Perinatal risk (ref. lower) } \\
\hline Moderate & 0.95 & {$[0.74-1.23]$} & 0.97 & {$[0.75-1.25]$} & 0.97 & {$[0.75-1.25]$} \\
\hline Higher & 1.02 & {$[0.79-1.34]$} & 1.09 & {$[0.82-1.46]$} & 1.09 & {$[0.82-1.46]$} \\
\hline Cerebral palsy & 1.89 & {$[1.35-2.64]$} & 2.08 & {$[1.44-3.00]$} & 2.08 & [1.45-3.00] \\
\hline Epilepsy & 1.85 & {$[1.07-3.21]$} & 1.92 & {$[1.07-3.46]$} & 1.91 & [1.06-3.43] \\
\hline Autism & 1.32 & {$[0.74-2.35]$} & 1.37 & {$[0.76-2.46]$} & 1.36 & {$[0.75-2.44]$} \\
\hline Moderate/severe vision or hearing problem & 1.37 & [0.90-2.10] & 1.65 & [1.01-2.69] & 1.66 & [1.02-2.69] \\
\hline \multicolumn{7}{|l|}{ Country (ref. mean) } \\
\hline Belgium & 0.82 & {$[0.54-1.25]$} & 0.70 & {$[0.44-1.11]$} & 0.70 & [0.44-1.11] \\
\hline Denmark & 2.46 & {$[1.83-3.31]$} & 2.91 & [2.03-4.19] & 2.90 & {$[2.02-4.16]$} \\
\hline Estonia & 0.73 & {$[0.42-1.25]$} & 0.75 & [0.41-1.38] & 0.75 & [0.41-1.38] \\
\hline France & 0.47 & {$[0.34-0.66]$} & 0.46 & {$[0.32-0.66]$} & 0.46 & {$[0.32-0.66]$} \\
\hline Germany & 1.39 & [0.94-2.07] & 1.47 & [0.93-2.32] & 1.47 & {$[0.93-2.31]$} \\
\hline Italy & 0.83 & {$[0.65-1.08]$} & 0.83 & {$[0.62-1.10]$} & 0.83 & [0.62-1.10] \\
\hline Netherlands & 0.61 & [0.32-1.15] & 0.52 & [0.27-1.02] & 0.53 & [0.27-1.02] \\
\hline Poland & 1.71 & [1.29-2.28] & 1.95 & [1.40-2.72] & 1.94 & [1.39-2.71] \\
\hline Portugal & 0.79 & [0.59-1.07] & 0.78 & [0.56-1.10] & 0.78 & [0.56-1.10] \\
\hline Sweden & 1.40 & [0.91-2.17] & 1.41 & [0.85-2.34] & 1.40 & [0.85-2.32] \\
\hline United Kingdom & 1.08 & [0.80-1.44] & 1.03 & [0.72-1.46] & 1.04 & [0.74-1.47] \\
\hline
\end{tabular}

All risk ratios are derived from multilevel generalized linear regression models, accounting for correlation between siblings 